Discussion

Papers

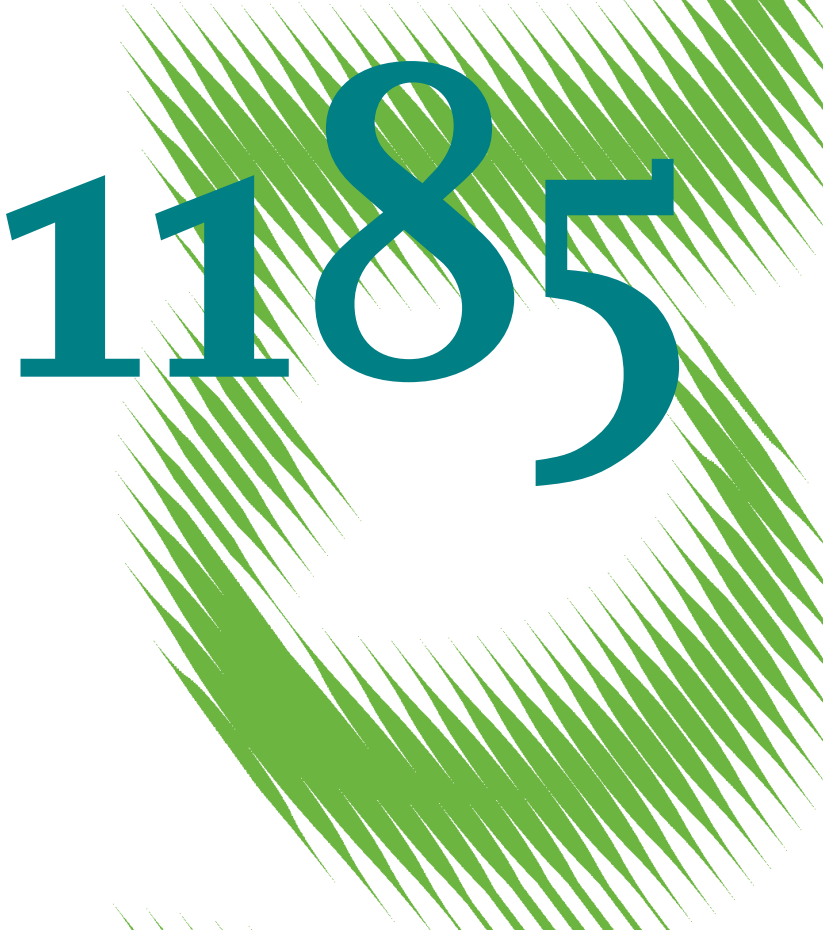

Evidence of Market Power in the Atlantic Steam Coal Market Using Oligopoly Models with a Competitive Fringe 
Opinions expressed in this paper are those of the author(s) and do not necessarily reflect views of the institute.

IMPRESSUM

(C) DIW Berlin, 2012

DIW Berlin

German Institute for Economic Research

Mohrenstr. 58

10117 Berlin

Tel. $+49(30) 89789-0$

Fax +49 (30) $89789-200$

http://www.diw.de

ISSN print edition $1433-0210$

ISSN electronic edition 1619-4535

Papers can be downloaded free of charge from the DIW Berlin website:

http://www.diw.de/discussionpapers

Discussion Papers of DIW Berlin are indexed in RePEc and SSRN:

http://ideas.repec.org/s/diw/diwwpp.html

http://www.ssrn.com/link/DIW-Berlin-German-Inst-Econ-Res.html 


\title{
Evidence of market power in the Atlantic steam coal market using oligopoly models with a competitive fringe*
}

\author{
Clemens Haftendorn \\ German Institute for Economic Research (DIW Berlin) \\ Mohrenstr. 58, 10117 Berlin, Germany \\ Tel. +49-30-89789-206, Fax +49-30-89789-113 \\ chaftendorn@diw.de
}

January 26, 2012

${ }^{*}$ I would like to thank Professor Benjamin F. Hobbs, Daniel Huppmann, Jan Abrell, Franziska Holz and the participants of the 2011 YEEES Seminar in Madrid for their helpful comments and suggestions. All remaining errors are mine. 


\begin{abstract}
Before 2004 South Africa was the dominant steam coal exporter to the European market. However a new market situation with rising global demand and prices makes room for a new entrant: Russia. The hypothesis investigated in this paper is that the three incumbent dominant firms located in South Africa and Colombia reacted to that new situation by exerting market power and withheld quantities from the market in 2004 and 2005. Three market structure scenarios of oligopoly with a competitive fringe are developed to investigate this hypothesis: a Stackelberg model with a cartel, a Stackelberg model with a Cournot-oligopoly as leader and a Nash-bargaining model. The model with a Cournot oligopoly as leader delivers the best reproduction of the actual market situation meaning that the dominant players exert market power in a non-cooperative way without profit sharing. Furthermore some methodological clarifications regarding the modeling of markets with dominant players and a competitive fringe are made. In particular we show that the use of mixed aggregated conjectural variations can lead to outcomes that are inconsistent with the actions of rational profit-maximizing players.
\end{abstract}

Keywords: Atlantic coal market, partial equilibrium modeling, market power

JEL Codes: L13, L72, C69, C72 


\section{Introduction}

The contribution of this paper is twofold. First some theoretical considerations regarding the market power representation in partial equilibrium modeling are made. Secondly, having found that certain approaches are problematic we propose and apply a different approach of modeling dominant firms with a competitive fringe to the Atlantic steam coal market. We show that in the years 2004 and 2005 the dominant firms in this market may have exerted market power.

A widely used approach in energy and resource modeling to model market power is the use of conjectural variations $(\mathrm{CV})$. This paper gives an overview of the theoretical literature of CV and presents an economic historiography of its use in applied partial equilibrium analysis. This paper also shows that this approach to represent market power may be problematic. In fact, we demonstrate that using the CV approach may lead to results that are in fact not Nashequilibria and do not represent the behavior of rational actors. This is especially the case when some actors have market power and others are assumed to behave competitively and is due to the fact that in its implementation the conjectural variation approach uses relative mark-ups between prices and marginal costs to represent market power. These mark-ups are used as equilibrium conditions but in certain cases these mark-ups may actually depreciate the profit of the players assumed to exert market power. This also relates to the problem that in the $\mathrm{CV}$ approach players exerting market power may be considered as "naive" as they may make false assumptions about how other players will react to their own actions.

Considering the shortcomings of the CV approach we use an alternative approach to model a dominant oligopoly with a competitive fringe based on the Stackelberg (1934) model. We then use three different ways to represent the dominant oligopoly: a non-cooperative Cournot oligopoly and two cooperative approaches, a cartel and a Nash bargaining model. These structural models are then applied to the Atlantic steam coal market in 2004 and 2005. Based on market observations we test the hypothesis that the incumbent firms located in South Africa and Colombia exerted market power by withholding quantities as a reaction to a new entrant, Russian, in order to keep the more expensive fringe players such as the US as marginal price setters. This represents a novel approach in partial equilibrium modeling of resource markets as we model companies and not countries. Our results show that the expected reaction seen in the actual market outcome can be best reproduced with the Cournot oligopoly model, suggesting that the dominant firms exerted market power in a non-cooperative way. 


\section{Literature Review}

Partial equilibrium models have been widely used to model energy and resource markets. The subjects of these analyses are broad, ranging from market structure investigations to infrastructure and policy analysis. Since the markets analyzed are often concentrated markets with only a few firms or players involved, modeling market power is necessary. One approach that has been extensively employed is the use of conjectural variations to model different market structures. This concept was first developed by Bowley (1924) and the term conjectural variation (CV) was introduced by Frisch (1933). It is used in static oligopoly models to describe that a player takes into account in his payoff maximizing decision that the other players might react to his decision. A formal description of the CV model as well as a literature overview and a critical assessment are provided in Section 3.

The application of CV to partial equilibrium models started in the 1980s with Kolstad and Wolak $(1983,1985)$ and their application to the coal trade in the Western US. In these models the players exerting market power are not companies using quantities as strategic decision variables but US states using a tax rate as decision variable in order to maximize their revenues. The $\mathrm{CV}$ component comes from the fact that the states have to make assumptions about how the other states will change their tax rates as a reaction to a their own tax rate change. A similar tax rate and CV approach has been used to model the international steam coal trade by Kolstad et al. (1983) and Kolstad and Abbey (1984). These coal market models use different assumptions about the $\mathrm{CV}$ values to see which market structure better represents trade. More recently Chen et al. (2006) used a tax CV model for the international rice trade with an optimization approach to find what $\mathrm{CV}$ values led to a better representation of trade flows. These tax CV models also allow for the representation of market power on the buyers side through the simulation, for example, of oligopsonies.

A second and recently more prolific stream of literature applies the traditional $\mathrm{CV}$ approach to model market power. Here, the CV represents an assumption about how other players will react in quantity changes to the players own quantity changes. This approach was first proposed by Nelson and McCarl (1984) and Kolstad and Burris (1986) who did the first application to the international wheat market. Various other applications followed in the agricultural field, for example Kawaguchi et al. (1997) for the Japanese milk market or for the international coking coal market in Graham et al. (1999). But it is really in the 2000s due to new advances in algorithms and solving methods that the use of CV models in the field of energy and resource modeling expanded greatly. We find applications to the electricity market 
in Bushnell (2003) and Chen et al. (2006). Another field where the CV approach has been used is in gas market modeling, for example by Zwart and Mulder (2006) and Egging et al. (2008, 2010). In the field of coal market modeling, which is the focus of the applied part of this paper, recent use of the CV approach was done by Paulus and Trüby (2011) and Paulus et al. (2011).

In order to model different market structure settings these papers use different values of $\mathrm{CV}$ for different players regarding the conjecture of how all the other aggregated players might react to a change in the players output. This is why we will call this approach mixed aggregated conjectural variation (MACV). This approach can be problematic, as we show in the next section.

\section{Critique of Conjectural Variation Models}

\subsection{Theory}

First we give a formal overview of the CV theory using the formulation of Figuières (2004) with two symmetric firms $i$ competing in quantities $q_{i}$ on a market for a homogeneous good. The inverse demand function and market price is $p=b-\sum_{i} q_{i}$ and the firms' productions costs are given by $C\left(q_{i}\right)=c q_{i}$ with $c$ strictly positive. The profit maximization of one firm $i$ is as follows:

$$
\max _{q_{i}} \prod_{i}\left(q_{i}, q_{j}\left(q_{i}\right)\right)=p q_{i}-c q_{i}
$$

$q_{j}\left(q_{i}\right)$ is the assumption of firm $i$ about how the other firm $j$ will set its quantities given firm $i$ 's quantities. This is the core assumption of the CV model. When we take the total derivative of $\Pi_{i}$ with respect to $q_{i}$ we obtain the following first order condition (FOC):

$$
b-\left(2 q_{i}+q_{j}\right)-c-q_{i} q_{j} \prime\left(q_{i}\right)=0
$$

which can be transformed into:

$$
p-c-\left(1+r_{i}\right) q_{i}=0
$$

where $r_{i}=q_{j}\left(q_{i}\right)$ is the CV, or firm i's conjecture, about the other firm $j$ 's reaction to a small change in $q_{i}$. Different values of the CV in Equation (3) yield different market outcomes. $r_{i}=0$ is the Cournot-Nash equilibrium, $r_{i}=-1$, is the Bertrand perfect competition outcome where prices equate marginal costs. Values higher than zero and up to 1 are also possible to model collusion and monopoly 
equilibria but we are more interested in non-cooperative market outcomes. Hence it is possible by setting the value of $r_{i}$ to any number between -1 and 0 to compute a range of equilibria that are thought to represent various degrees of competition or market power as stated for example by Egging et al. (2008). In the following we evaluate this statement carefully as what seems to be an easy and straightforward way to deal with imperfect competition can lead to counter-intuitive and unsatisfactory results.

But before we critically assess the application of the CV model we give a quick overview of the theoretical CV literature. As pointed out in the previous section the concept of CV is old and dates back to Bowley (1924). However, due to the fact that in the traditional CV equilibrium (CVE) the conjectures are exogenous, any arbitrary equilibrium can be computed and these equilibria are not grounded in refutable economic theory (see Figuières, 2004). Laitner (1980) identified that when using CVE a consistency problem arises as a large set of possible output combinations and conjectures can satisfy the equilibrium conditions. Therefore, a new stream of literature arose with Laitner (1980), Bresnahan (1981) and Perry (1982) where the conjectures are required to be rational or consistent. These conditions require that the expectations expressed in the $\mathrm{CV}$ be met by the actual behavior of the players in equilibrium or in the neighborhood of equilibrium (see Figuières, 2004). However, this approach has also been criticized as not representing the behavior of profit maximizing firms by Makowski (1987). Also, Lindh (1992) finds that this concept leads to circular reasoning and that in the case of rational behavior based on common knowledge Cournot or Stackelberg equilibria are the only possible equilibria. The main critique of $\mathrm{CV}$ models come from the time component. As Vives (2000) puts it, the CV approach "attempts what seems impossible - the consideration of dynamics in a static model" as a player takes into account possible reactions of the other players, but the other players will actually not react. Also the expectation need not and might not be correct (see Friedman, 1983).

Figuières (2004) view on the CV from a theoretical perspective is that it may provide useful "shortcuts" to capture more complicated models in the absence of complete information, common knowledge or a proper dynamic formulation. However this is not how the applied partial equilibrium literature has used this approach.

\subsection{Partial equilibrium modeling applications}

As shown in the literature review the first application of CV dates back to the early 1980s when the consistent CV model was developed and first critiques (for example in Friedman, 1983) of both CVE and consistent CVE arose. Regardless of those 
theoretical considerations applied researchers started using two features of CV models that had never really been studied by the theoretical literature. First, different values of $r_{i}$ for each player are used since the setting is usually more complex than the duopoly models of the theoretical literature. Secondly, aggregated conjectural variations, that treat all the other players as one reacting to the player's quantity in a unique way, are introduced. These features explain the name mixed aggregated conjectural variation (MACV) that we introduced for these kind of models.

One especially common feature of MACV models is to use Equation (3) with a value $r_{i}=0$ for the dominant players and $r_{i}=-1$ for the competitive fringe. This is problematic from point of view of rationality and complete information since this represents a situation where the dominant players naively consider the actions of the fringe as given (see Gabriel and Smeers, 2006), as if the fringe players were also Cournot players. Smeers (2008) further argues that, given the ambiguous nature of the MACV model, a simpler way to model imperfect competition would be to use a mark-up on the perfect competition price which is as arbitrary as using CV. As a matter of fact using a MACV model does nothing else than imposing a relative mark-up on marginal costs and cannot be considered as a model of rational profitmaximizing players.

Let us consider the case of a player with the $\mathrm{CV}$ of $r_{i}=0$. In that case the first order condition is the same as in the Cournot-Nash equilibrium and if all other players behave also as Cournot-Nash players, his FOC yields the non-cooperative profit-maximization solution. Reorganizing Equation (2) and introducing parameter $a$ as the slope of the inverse demand function as well as $C \prime\left(q_{i}\right)$ as an increasing marginal cost function, we obtain following expression for the first order condition:

$$
a q_{i}=b-a q_{i}-a q_{j}-C \prime\left(q_{i}\right)
$$

Given that the price is $p=b-a q_{i}-a q_{j}$ we can see that $a q_{i}$ represents the mark-up as difference between price and marginal costs. This mark-up is relative as it depends on $q_{i}$. We can see it as a percentage mark-up that defines the markup to equal a percentage $a$ of the quantity supplied. It is at this point that, if not all the players are Cournot-Nash players, we depart from the idea of profit maximizing players. What the player does in this case according to Equation (4) is to maintain this percentage mark-up. By inspection we can determine what happens when player $j$ behaves competitively with a CV of $r_{j}=-1$, or a zero mark-up. In comparison to the Cournot-Nash case $q_{j}$ will increase. As a reaction and to keep the percentage mark-up and keep the price above the competitive level, player $i$ will decrease its quantity $q_{i}$. In the case of two symmetric firms with the same cost 
functions, the competitive firm will equate price to marginal costs. But the firm supposedly exerting market power and subject to the same market price will further reduce it's quantity to hold the mark-up objective. This lowered quantity causes its profit to be actually lower than if it had behaved competitively with $r_{i}=-1$. A more formal and differentiated proof of this occurrence is given in Ulph and Folie (1980). Here we have the first demonstration that the MACV model may lead to counter-intuitive and unsatisfactory results as the player supposedly having market power would be better off by exerting less market-power or requiring a lower markup. We can derive formally what the optimal mark-up would be.

In the spirit of Laitner (1980), Daughety (1985) and Dockner (1992) that use dynamic formulations to analyze CV models, we use a sequential formulation of the MACV model allowing the two players $i$ and $j$, starting with the one that is worse off in comparison with its expectations, to revise and choose their CV value $r_{i}$ optimally. The first order condition of $i$, and similarly $j$, is:

$$
b-2 q_{i}-q_{j}-C \prime\left(q_{i}\right)-r_{i} q_{i}=0
$$

Furthermore we use the following proposition from Kolstad and Wolak (1986): "assuming a quadratic duopoly model with conjectural variations no smaller than -1 , and with identical cost structures for the two firms, the equilibrium output for each firm is monotone with respect to each of the conjectural variations":

$$
\partial q_{i}^{*} / \partial r_{i}<0, \quad \partial q_{i}^{*} / \partial r_{j}>0
$$

Proposition 1: Given that the players $i$ and $j$ are symmetric with constant marginal costs, one player can always increase its profit by reducing its $C V$ value $r_{i}$. The only stable solution is $r_{i}=r_{j}=-1$. The optimal value for $r_{i}$ given the other player's $C V$ is:

$$
r_{i}=-\frac{1}{2+r_{j}}
$$

The proof is in Appendix 1. This proposition shows that in the simplest setting of the MACV model the "exercise of more market power" is detrimental to the player. If the player is given the possibility to determine his $\mathrm{CV}$ in a profit maximizing way, he will in fact want to "exert less market power" and have a lower mark-up.

Proposition 2: If we introduce capacity constraints to the above model, and given that the capacity of player $j$ is binding when $r_{i}=0$, then $r_{i}=0$ is the optimal profit-maximizing strategy for player $i$. In the case that the capacity constraints are 
not binding the rule of proposition 1 applies.

Appendix 1 to this paper supplies a proof. This case highlights a situation where the application of the MACV model may be valid. If we consider that player $i$ exerts full market power with $r_{i}=0$ and player $j$ acts as the competitive fringe with $r_{j}=-1$ and has a binding capacity constraint, this model is equivalent to the dominant firm competitive fringe model where the dominant firm equates marginal revenues to marginal costs and takes the actions of the fringe as given.

This also relates to the result of Ulph and Folie (1980) that show that the incentive to behave as Cournot-Nash players depends on the relative steepness of the slope of the supply or cost function of the fringe. In the case of a binding capacity constraint this slope becomes infinite. In the next proposition we show how the slope of the competitor influences the optimal CV value.

Proposition 3: Introducing heterogeneous cost functions of the form $C\left(q_{i}\right)=$ $\left(\right.$ Cint $\left._{i}+{ }_{1}^{1 / 2} C \operatorname{slp}_{i} q_{i}\right) q_{i}$ with Cint $_{i} \geqslant 0$ the marginal cost function's intercept and $C s l p_{i}>0$ the marginal cost function's slope, the optimal profit maximizing choice for player $i$ is given by:

$$
r_{i}=-\frac{1}{2+C s l p_{j}+r_{j}}
$$

for $q_{j}>0$. If $q_{j}=0$, player $i$ should increase $r_{i}$ until $p+\epsilon=$ Cint $_{j}$ with $\epsilon$ an infinitesimally small number. This latter strategy represents the limit-pricing strategy where an incumbent prevents the entry of a competitor in the market.

The proofs are in Appendix 1. Equation (8) shows that "exerting more market power" than the opponent, or $r_{i}>r_{j}$, can be the optimal strategy if the opponent's slope $C s l p_{j}$ is high enough. The steeper the slope, the higher $r_{i}$ can be. However, since the value of $r_{i}=0$ can never be reached and very high marginal cost function's slopes of the fringe may not be realistic, this formulation of the MACV model remains problematic. It is also interesting to note that the setting where the players can sequentially correct their $\mathrm{CV}$, the above rule of Proposition 3 has no stable converging solution.

We have seen that apart from the case where the competitive fringe has a binding capacity constraint using the MACV approach in a quantity setting to model a dominant oligopoly with a competitive fringe cannot be done properly. This is due to the fact that the MACV model leads to a representation of players that are not profit-maximizing rational actors, but naive margin-constrained players. This can, for example, be seen in the MACV application to the coking coal market by Graham 
et al. (1999), where the MACV is implemented as an actual constraint in a revenue maximizing problem.

As seen in the literature review, the first applications of the CV approach were done through tax models of revenue maximization. The players are assumed to be public governmental authorities that maximize a revenue $R_{i}=\pi_{i} q_{i}$ by choosing a tax rate $\pi_{i}$. The producers of the resource are assumed to be competitive price takers and the taxing authorities choose the optimal tax rate given the CV about how the other tax authorities might react to a change of $\pi_{i}$. The first order conditions of this problem are:

$$
\begin{gathered}
q_{i}+\pi_{i} \frac{d q_{i}}{d \pi_{i}}=0 \\
p-\pi_{i}-C \prime\left(q_{i}\right)=0
\end{gathered}
$$

To actually solve the problem, we would have to incorporate the CV by taking the total derivative of expression (10). For a formal description of the model see Kolstad and Wolak (1983, 1985). Applying the same arguments as above for Equation (4) and using the above conditions (9) and (10) shows that the tax MACV model does not present the same problem as the quantity CV market model. If the player $i$ makes a false conjecture about player $j$ and a higher quantity $q_{j}$ is supplied to the market causing price $p$ to fall, player $i$ has the possibility to lower the tax rate and increase $q_{i}$ so that condition (9) is still respected. The tax rate here is nothing else than the mark-up and since the players have a direct possibility to influence it, the tax MACV model leads to an optimal revenue solution whereas the quantity MACV model does in most cases not lead to a maximum profit solution. The tax MACV model also prevents unsatisfactory outcomes where players exerting market power would earn less than if they behaved competitively. This is due to the fact that for decreasing values of $\pi_{i}$, condition (10) converges to the solution where price equals marginal costs. This is also shown graphically in Kolstad and Wolak (1986, Figure 2 ). However the problem of rationality remains as players could be better off in the case that their conjectures about the tax adjustment of the other players to their tax change is false.

We have seen that even in their simplest formulation MACV models can be highly problematic to represent rational actors in a market with imperfect competition. As Ralph and Smeers (2006) put it, the CV approach is "discredited as a theoretical explanation of market power but it allows representing it". Therefore the MACV approach is valid if there is an uncertainty about the structure of a market and when $\mathrm{CVs}$ are used in a calibration process to replicate the market. However using 
the MACV approach for multi-period models (therefore assuming the same unclear market structure as today) or in order to investigate market structures seems to be a meander not to follow since the CV approach is not grounded in economic theory. We show other models more suited to model dominant players with a competitive fringe in Section 5 .

\section{Developments in the Atlantic Steam Coal Market in the Early 2000s}

The international trade of steam coal for electricity generation developed in the wake of the two oil crisis in 1973 and 1979 when more coal power plants started to be built using inexpensive imported coal. Until the mid-2000s the international steam coal trade was separated in two relatively distinct markets: the Atlantic market and the Pacific market. In the Atlantic market the main importer is Europe and the most important suppliers are South Africa, Colombia, Russia and the US. The importers in the Pacific market are the Asian developing or developed economies such as Japan, South Korea, Taiwan and India, supplied mainly by Australia, Indonesia and China. The focus of the present paper is on the Atlantic steam coal market and the market that we study is the European steam coal import market. European steam coal imports grew from around 50 million tons (Mt) in 1978 to more than $100 \mathrm{Mt}$ in 1990 and more than $200 \mathrm{Mt}$ in 2007 (IEA, 2011). One other characteristic in the Atlantic market is the evolution of the contract nature from long-term contracts (up to 10 years) before the 1980s to cargo based short term spot contracts that represented approx. 80\% of trade in 2003 (see Ekawan and Duchêne, 2006). The price indices can be FOB (free on board) at the export port and CIF (cost insurance freight) at the import port. ${ }^{1}$ Figure 1 shows the development of the main indices for the Atlantic market in the 2000s. The FOB prices are from South Africa (Richards Bay) and Colombia (Puerto Bolivar). The CIF index is the main European import marker ARA (Amsterdam, Rotterdam, Antwerpen).

As we can see in Figure 1, the two FOB price indices from South Africa and Colombia are on a similar level most of the time with the Colombian coal priced slightly higher since it has a higher energy content of approx. $6300 \mathrm{kcal} / \mathrm{kg}$ than the South African coal. However we can distinguish two periods where there is a notable price difference (circled in Figure 1). The period in 2009 where South African coal is priced higher than the Colombian can be explained by the fact that South Africa

\footnotetext{
${ }^{1}$ There is no central commodity exchange where steam coal is traded. The price indices are based on reported deals (spot: delivery three months ahead) submitted by traders to different organizations such as Platts that collect and publish this information.
} 


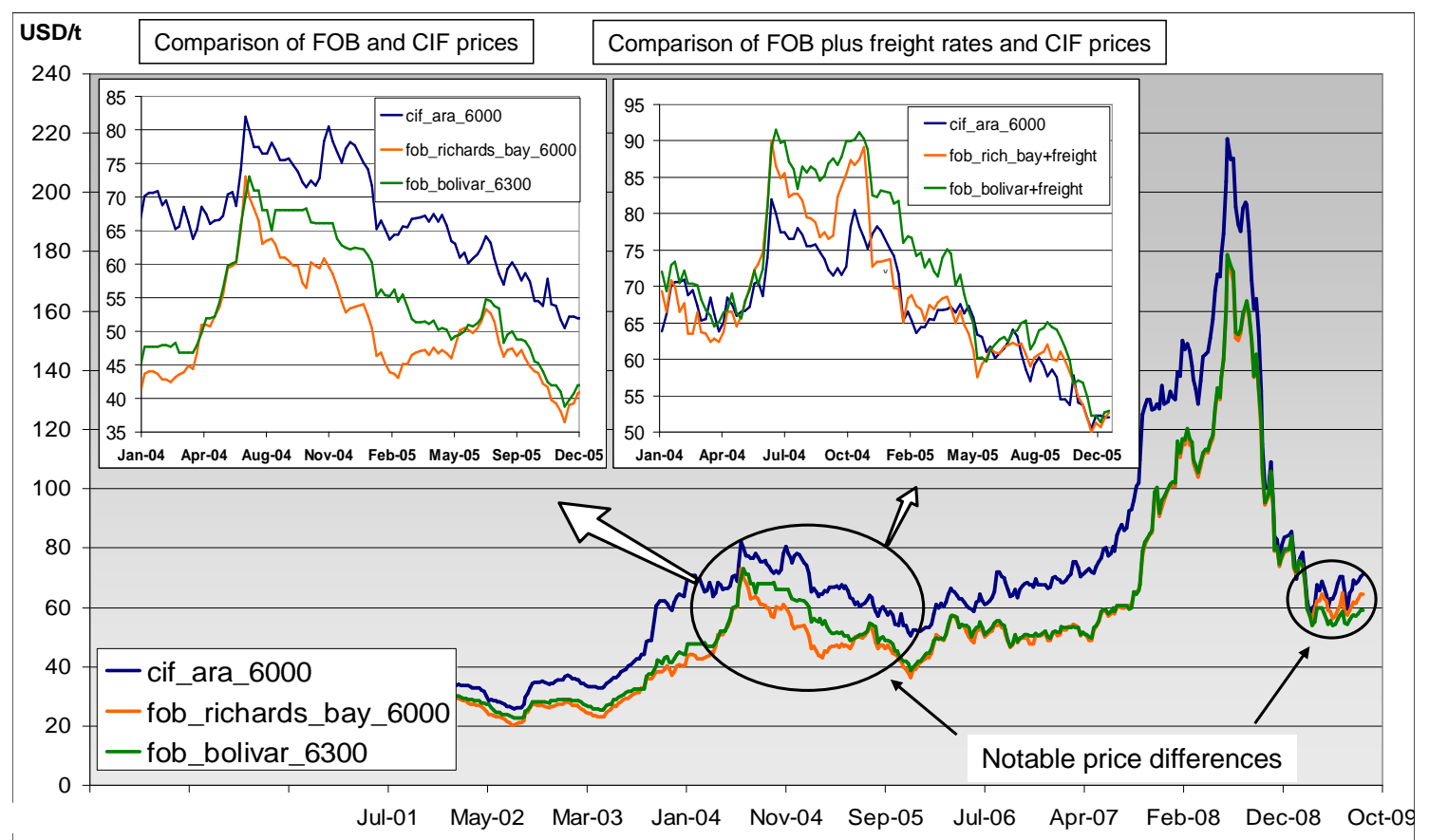

Figure 1: Price developments in the Atlantic steam coal market in the 2000s (Source: Platts data)

started exporting significant amounts of coal to India (more than $20 \mathrm{Mt}$, see Table 4 in Appendix 2) which influenced the price-setting upwards. The second divergence happened in 2004 and 2005 where Colombian coal was priced significantly higher. The upper left graph included in Figure 1 shows a "zoom" of this period. It seems that the FOB Richards Bay price follows the CIF ARA price more closely whereas the FOB Bolivar price lags in the general price decline observed in 2004 and 2005. In the upper right graph we compare the CIF prices to the FOB price plus the freight rate on that specific route. In a well functioning market those prices should be in a close range like it is the case in the first half of 2004 and the second half of 2005. However, in the period in-between we see the counter-intuitive phenomenon where the FOB plus freight prices are higher than the CIF ARA price. The South African prices normalize by the beginning of 2005 but the divergence remains in the Colombian prices until mid-2005. These divergences may be a sign of the market power abuse we want to investigate in this paper.

Indeed there is potential to exert market power in the Atlantic market as the market is dominated by three mining giants, the "big three": BHP Billiton, Anglo American and Xstrata that are present in South Africa and Colombia. In Table 4 (in Appendix 2) we see that the share of South Africa and Colombia in European imports is high, but declining: $61 \%$ in 2002 and 52\% in 2005. The share of the "big three" in the export of both countries is also high, around $80 \%$ (see Table 5 in 


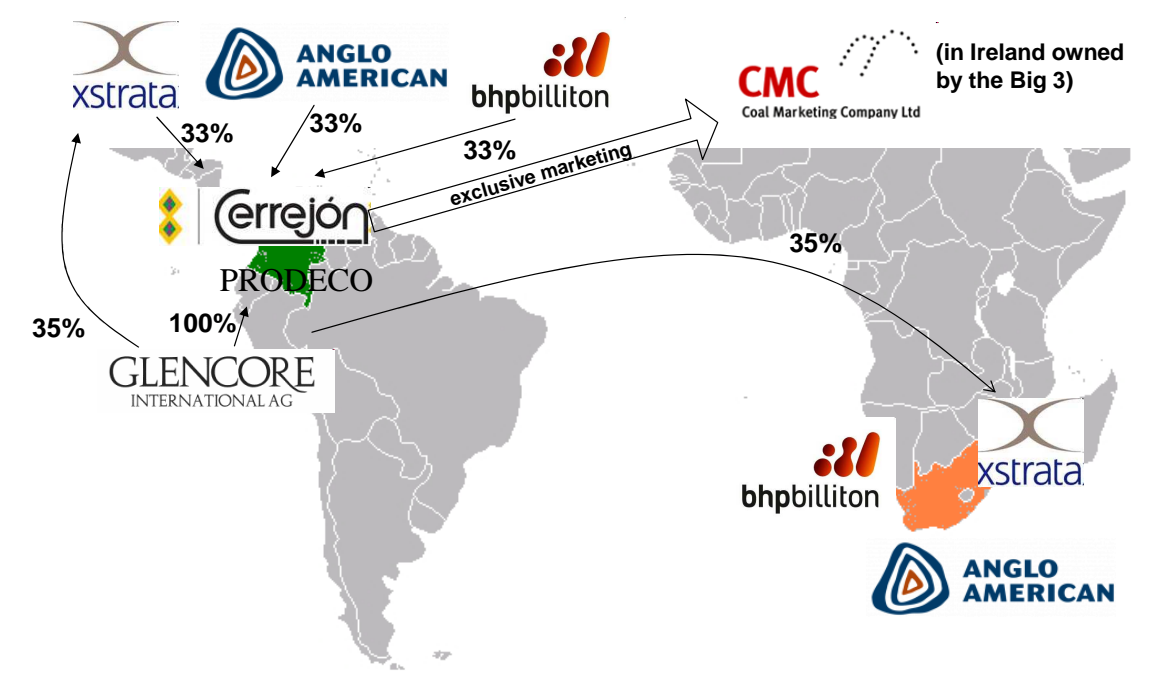

Figure 2: Market structure of the coal market in South Africa and Colombia in the early 2000s

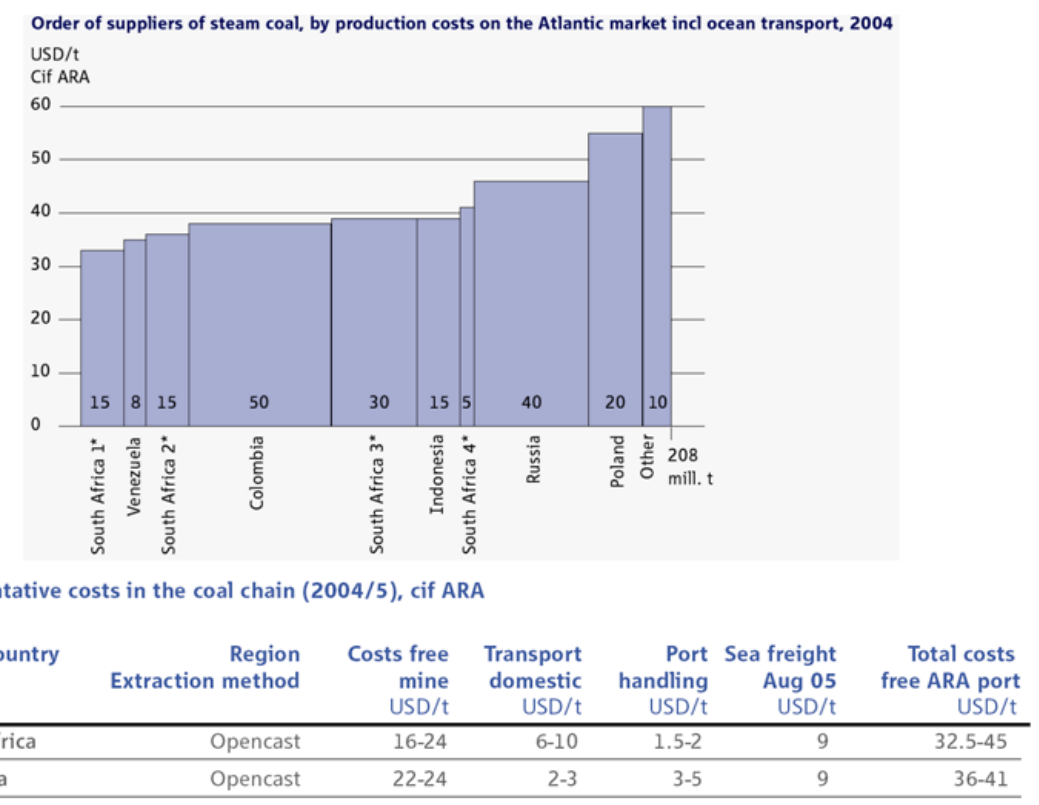

Figure 3: Costs and merit-order of suppliers in the Atlantic steam coal market in 2004/05 (Source: Ritschel and Schiffer, 2007) 
Appendix 2). This concentrated market structure is reinforced by the fact that in Colombia the "big three" own the largest coal mine Cerrejón and market the coal together. The other important coal company in Colombia, Prodeco, is owned by the international trading company Glencore that owns 35\% of Xstrata. This complex ownership structure is illustrated in Figure 2.

The focus of our analysis is on the years 2004 and 2005. As we can see in Table 5 in Appendix 2 during those years South Africa reduced its exports to Europe whereas Colombia increased them slightly and Russia expanded significantly. Indeed we can see in the merit-order of suppliers in Figure 3 that Russia supplies Europe at approx. $45 \mathrm{USD} / \mathrm{t}$ and it is after this mark in the CIF ARA price was passed for the first time during the year 2003 that Russia expanded its exports dramatically.

The hypothesis we examine in this paper is that the incumbent oligopoly formed by the "big three" reacted to the entry of the new competitive player Russia by exerting market power by withholding quantities of South Africa exports. South Africa has some mines that have quite expensive production costs so the withholding strategy makes sense there and not in Colombia. By withholding quantities the incumbent oligopoly tried to maintain high prices in 2004 and 2005 by keeping expensive marginal fringe players in the market, especially the US. This is the hypothesis we will examine in the next modeling section by modeling the strategic behavior of the incumbent oligopoly reacting to a change of the supply of an aggregated competitive fringe.

\section{Market power models with dominant players and a competitive fringe}

\subsection{Modeling the competitive fringe}

An alternative way to model a dominant oligopoly with a competitive fringe that could prove to be more satisfactory than MACV model discussed above are models of the Stackelberg type. In a Stackelberg game the dominant player, or leader, is not naive like in the MACV approach but fully informed about the decisions of the fringe, or followers, and can take them into account in its own decision. The classical Stackelberg (1934) model was developed for the case of one leader and one follower. Sherali (1984) expanded it for the case of multiple leaders and followers but with the restriction that the leaders are symmetrical. One problem that can arise with the multiple-leader formulation are multiple equilbria. This is due to the fact that the reaction function of the followers that enters the problem of the leader is nonsmooth 
as they produce either a quantity that is a function of the leaders output or zero. Ehrenmann (2004) show that this problem can arise even in a very simple setting with two symmetric leaders and one follower. However more recent work by $\mathrm{Xu}$ (2005) and DeMiguel and $\mathrm{Xu}$ (2009) shows that under certain conditions unique solutions can be reached, in particular that the fringe players do not have a binding capacity limit. In our analysis we model the competitive fringe as a single player and ensure that the fringe always provides a positive quantity, hence we get unique solutions.

The quantity of the fringe $q_{f}$ as a function of the quantity of the leaders $Q_{l}$ shown in Equation (13) is obtained by transforming the first order conditions (12) of the profit maximization problem (11) after removing the expression $-a \cdot q_{f}$ from (12) so that we model the fringe as competitive player that equates the price to its marginal costs. Parameters $b$ and $a$ are respectively the demand intercept and slope and Cint $_{f}$ and $C s l_{f}$ the slope and intercept of the marginal cost function.

$$
\begin{gathered}
\max _{q_{f}} \Pi_{f}=\left\{b-a\left(q_{f}+Q_{L}\right)\right\} q_{f}-\left(\text { Cint }_{f} \cdot q_{f}+\frac{1}{2} C \operatorname{slp}_{f} \cdot q_{f}^{2}\right) \\
\frac{\partial \prod_{f}}{\partial q_{f}}=b-a\left(q_{f}+Q_{L}\right)-\left(1+r_{f}\right) a \cdot q_{f}-\text { Cint }_{f}-C \operatorname{slp}_{f} \cdot q_{f} \stackrel{!}{=} 0
\end{gathered}
$$

Assuming that the fringe is a competitive player then $r_{f}=-1$ and

$$
q_{f}=\frac{b-a \cdot Q_{L}-\operatorname{Cint}_{f}}{a+C \operatorname{sl} p_{f}}
$$

In the following section we discuss possible alternatives to model the dominant oligopoly so as to reflect the market structure of the Atlantic coal market with the "big three" companies.

\subsection{Cournot oligopoly as Stackelberg leader}

We can now integrate the quantity of the competitive fringe into the optimization problem (14) of the leaders $l$. The leaders can operate in different countries $e$, so they maximize their profit by choosing their optimal quantities $q_{l e}$ to produce and sell given country-specific quadratic production costs and production capacity constraints $\mathrm{Cap}_{l e}$. 


$$
\begin{aligned}
\max _{q_{l e}} \Pi_{l}= & \left\{b-a\left[\sum_{l} \sum_{e}\left(q_{l e}\right)+\frac{b-a \cdot \sum_{l} \sum_{e}\left(q_{l e}\right)-C i n t_{f}}{a+C s l p_{f}}\right]\right\} \sum_{e}\left(q_{l e}\right) \\
& -\sum_{e}\left(\operatorname{Cint}_{l e} \cdot q_{l e}+\frac{1}{2} C s{ } p_{l e} \cdot q_{l e}^{2}\right) \\
& \text { s.t. } \quad \operatorname{Cap}_{l e} \geqslant q_{l e}\left(\lambda_{l e}\right)
\end{aligned}
$$

The optimization problem (14) leads to the following Karush-Kuhn-Tucker (KKT) conditions (15) after deriving the Lagrangian function with respect to the decisions variables and dual variables.

$$
\begin{aligned}
0 \leqslant \frac{\partial L_{l e}}{\partial q_{l e}} & =-b+a\left(\sum_{l} \sum_{e}\left(q_{l e}\right)+\frac{b-a \cdot \sum_{l} \sum_{e}\left(q_{l e}\right)-C i n t_{f}}{a+C s p_{f}}\right) \\
& +\left(a-\frac{a^{2}}{a+C s p_{f}}\right) q_{l e}+C \operatorname{Cint}_{l e}+C \operatorname{slp} p_{l e} \cdot q_{l e}+\lambda_{l e} \perp q_{l e} \geqslant 0 \\
0 \leqslant \frac{\partial L_{l e}}{\partial \lambda_{l e}} & =C a p_{l e}-q_{l e} \perp \lambda_{l e} \geqslant 0
\end{aligned}
$$

This model in its complete form with the upper level equilibrium problem of the leader and the lower-level equilibrium problem of the fringe is actually an equilibrium problem with equilibrium constraints (EPEC). It can be numerically solved in the mixed complementarity format (MCP) using the PATH solver (see Ferris and Munson, 2000). This model formulation represents the case where the members of the "big three" dominant oligopoly act in a strategic non-cooperative manner knowing how the other strategic players as well as the fringe react to their actions.

\subsection{Stackelberg-Cartel model}

The Stackelberg-Cartel model formulation is the closest to the original Stackelberg (1934) formulation. The leader acts as a single profit maximizing unit incorporating all the players and their production countries $e$ that are member of the cartel. What is being maximized is a single joint profit under the assumption that a financial transfer between the cartel members in possible. This problem can be modeled as a mathematical problem with equilibrium constraints (MPEC, see Dirkse and Ferris, 1999) because one maximizes the profit of the cartel under the equilibrium constraints of the fringe and the market clearing condition that defines the price $p$ depending on the total quantity supplied to the market $Q$. 


$$
\begin{aligned}
& \max _{q_{e}} \Pi_{l}= p \cdot \sum_{e}\left(q_{e}\right)-\sum_{e}\left(\text { Cint }_{e} \cdot q_{e}+\frac{1}{2} \operatorname{Cslp}_{e} \cdot q_{e}^{2}\right) \\
& \text { s.t. } \quad \operatorname{Cap}_{e} \geqslant q_{e} \\
& 0 \leqslant-p+C i n t_{f}+C \operatorname{slp} p_{f} \cdot q_{f} \perp q_{f} \geqslant 0 \\
& p=b-a \cdot Q, \quad p(\text { free })
\end{aligned}
$$

This model can be solved in GAMS with the non-linear programming (NLP) solver CONOPT as an MPEC class of model (see Ferris et al., 2002).

\subsection{Nash-Bargaining model}

The Nash-Bargaining model is also a cooperative equilibrium between players but without the possibility of financial transfer. This may be more realistic in the case of the "big three" since they operate as separate entities in South Africa. The players jointly choose the totally supplied quantities that are optimal for each of them. A numerical solution method including stability conditions was first developed in Harrington et al. (2005). In their formulation of the Nash bargaining game, players maximize the product of the difference between the profit of a new cooperative equilibrium and the profit of the non-cooperative Cournot-Nash equilibrium $\Pi_{l}^{N}$ so that all players are better off in the Nash Bargaining solution. Similarly to Harrington et al. (2005) we use optimization under constraint to obtain a numerical solution.

$$
\begin{aligned}
\max _{q_{l e}} \Pi_{l}=\prod_{l}\left(\left\{b-a\left[\sum \sum_{e}\left(q_{l e}\right)+\frac{b-a \cdot \sum_{l} \sum_{e}\left(q_{l e}\right)-\text { Cint }_{f}}{a+C s l p_{f}} \sum_{e}\left(q_{l e}\right)\right.\right.\right. \\
\left.-\sum_{e}\left(\operatorname{Cint}_{l e} \cdot q_{l e}+\frac{1}{2} C \operatorname{slp} p_{l e} \cdot q_{l e}^{2}\right)-\Pi_{l}^{N}\right) \\
\text { s.t. } \quad \text { Capple }_{l} \geqslant q_{l e}
\end{aligned}
$$

This model can be solved in GAMS as a NLP using the solver CONOPT.

\section{Application to the Atlantic Steam Coal Market}

\subsection{Model specification and data}

In this section we present the detailed data of our market structure analysis. In the years 2004 and 2005 the Atlantic steam coal market was dominated by a multi- 
location oligopoly composed of the "big three" mining companies Anglo American, BHP Billiton and Xstrata active in South Africa and Colombia. We analyze how this oligopoly may have used its market power by reacting strategically to the arrival of a new entrant in the market: Russia.

\begin{tabular}{|c|c|c|c|c|c|c|}
\hline & \multicolumn{3}{|c|}{2004} & \multicolumn{3}{|c|}{2005} \\
\hline & MC Int. & MC Slope & P. Cap. & MC Int. & MC Slope & P. Cap. \\
\hline S. Africa & & & 60 & & & 60 \\
\hline AngloAm & 36 & 1.100 & 20 & 36 & 1.100 & 20 \\
\hline BHPB & 36 & 0.880 & 25 & 36 & 0.880 & 25 \\
\hline Xstrata & 36 & 1.467 & 15 & 36 & 1.467 & 15 \\
\hline Colombia & & & 25 & & & 26 \\
\hline AngloAm & 43 & 0.360 & 8.33 & 43 & 0.346 & 8.66 \\
\hline BHPB & 43 & 0.360 & 8.33 & 43 & 0.346 & 8.66 \\
\hline Xstrata & 43 & 0.360 & 8.33 & 43 & 0.346 & 8.66 \\
\hline Fringe & & & & & & \\
\hline Russia, US & 29 & 0.850 & $\infty$ & 29 & 0.680 & $\infty$ \\
\hline
\end{tabular}

Table 1: Producer data: marginal cost parameters (intercept and slope) in USD/t and production capacities in million tons per year (Source: own after: Ritschel and Schiffer, 2007, Baruya, 2007, IEA, 2011 and company reports)

Table 1 presents the producer data and the data sources. In South Africa production costs and capacity did not change between 2004 and 2005 and Colombia added 1 million tons per year (Mtpa) of capacity in 2005. The fringe aggregates the competitive players, mainly Russia and the US, but since the capacity is not limited it also represents potential entrants from the Pacific coal market. The main change between 2003 and 2005 is the annual addition of 10 Mtpa of capacity in Russia from $30 \mathrm{Mtpa}$ in 2003 to $40 \mathrm{Mtpa}$ in 2004 and finally to $50 \mathrm{Mtpa}$ in 2005. Since Russia is the cheapest producer in the "merit-order" curve of the fringe this is represented by a lowering of the fringe's marginal cost slope.

We construct one linear demand curve for European steam coal imports using the following reference data: reference price $p_{\text {ref }}=55 \mathrm{USD} / \mathrm{t}$, reference quantity $Q_{\text {ref }}=160 \mathrm{Mt}$ and a price elasticity of demand $\epsilon=-0.3$. Price and quantities are taken from IEA, 2011, the elasticity as well as the methodology are from Haftendorn and Holz (2010). Since the European demand was stable between 2004 and 2005 we take the same demand data for both years.

\subsection{Results}

The results for the market structure scenarios introduced in Section 5 for the years 2004 and 2005 are shown in Table 2. Additionally to the Cournot oligopoly, the 
Cartel and the Nash bargaining cases this table also presents the perfect competition case as a benchmark (modeled as MCP, see Haftendorn and Holz, 2010).

\begin{tabular}{|r||c|c||c|c||c|c||c|c|}
\hline \multicolumn{1}{|c||}{} & \multicolumn{2}{c||}{ Cournot } & \multicolumn{2}{c||}{ Cartel } & \multicolumn{2}{c||}{ Nash-Barg. } & \multicolumn{2}{c|}{ Perfect C. } \\
\hline & $\mathbf{0 4}$ & $\mathbf{0 5}$ & $\mathbf{0 4}$ & $\mathbf{0 5}$ & $\mathbf{0 4}$ & $\mathbf{0 5}$ & $\mathbf{0 4}$ & $\mathbf{0 5}$ \\
\hline \hline Big 3 S.A. (Mt) & 52.4 & 43.8 & 43 & 40 & 42.9 & 39.9 & 60 & 60 \\
\hline Big 3 Col. (Mt) & 25 & 26 & 25 & 26 & 25 & 26 & 25 & 26 \\
\hline Fringe (Mt) & 60.5 & 70.8 & 65.8 & 73.2 & 65.9 & 73.2 & 56.1 & 60.7 \\
\hline \hline Price (USD/t) & 80.4 & 77.2 & 85 & 78.8 & 84.9 & 78.8 & 76.7 & 70.3 \\
\hline
\end{tabular}

Table 2: Modeling results for the traded quantities in Mt and the prices in USD $/ \mathrm{t}$ in 2004 and 2005 for the four market structure scenarios.

The strategic reaction of the incumbent cartel to the entry of Russia can be seen in all three market power cases where we see a reduction of supplies from South Africa below the competitive benchmark in 2004 and 2005. In the perfect competition case South Africa produces at full capacity. The results of the cartel and Nash bargaining simulations are almost identical because the players have similar cost functions and the capacity retrictions are not binding in South Africa and equally binding in Colombia.

Proposition 4: In the case of a duopoly with two symmetrical players $i$ with zero production costs the produced quantities $q_{i}$ will be the same if they behave as a cartel or as Nash bargaining competitors: $q_{i}^{C}=q_{i}^{N B}=\frac{b}{4 a}$ with a and $b$ respectively the demand curve slope and intercept.

Appendix 1 provides a proof but the intuition is straightforward. Since the players are identical, they have identical benefits from withholding their supplies and do not need financial transfers between players. Hence they can reach the same monopoly solution of the cartel case in the Nash bargaining competition.

If we look again at the simulated quantities in Table 2, the magnitude of the supply withholding in the Cournot oligopoly case is more in line with the observed quantities (see Tables 4 and 5 in Appendix 2) than in the Cartel and Nash bargaining cases where the supplied quantities are significantly smaller. This suggests that players may have exerted market power in a non-cooperative way. Even if the "big three" actually cooperate in Colombia by owning a mine and marketing its coal together, the strategic decision to exert market power is to reduce supplies from South Africa where the "big three" are independent players.

If we look at the quantities supplied by the "big three" in South Africa the simulated results in 2004 of $52.4 \mathrm{Mt}$ are quite similar to the actual quantity of $51 \mathrm{Mt}$ shown in Table 5. However, this is not true for 2005 where the simulated withholding is too high and the companies in reality increased production again. This mismatch 
of results and observations is due to the yearly time resolution of our analysis and the fact that the time frame where that market power was supposedly used stretches from mid-2004 to mid-2005, with a stronger effect in 2004 (see 4, Figure 1). In the second half of 2005 the "big three" may have stopped their strategic withholding and this is why they exported more. Additionally, timing is a difficult issue in this analysis as the benchmark values can differ in time. The price indices are for price deliveries three months ahead and there is a time difference between exports and imports on which our yearly analysis is somewhat artificially imposed.

In order to see if this effect was only relevant in the years 2004 and 2005 or existed before and after we implement some additional simulations for the years 2003 and 2006 for the Cournot oligopoly case and the perfect competition case. Regarding the data we assume production costs in 2003 about 10 to 20 per cent lower than in 2004 and used the following reference prices and quantities for 2003 and 2006: $p_{\text {ref }}^{2003}=45 U S D / t, Q_{r e f}^{2003}=140 M t, p_{r e f}^{2006}=60 U S D / t$ and $Q_{r e f}^{2006}=175 M t$. Table 3 shows the results.

\begin{tabular}{|r||c|c|c|c||c|c|c|c|}
\hline \multicolumn{1}{|c||}{} & \multicolumn{3}{c||}{ Cournot Oligopoly } & \multicolumn{4}{c|}{ Perfect Competition } \\
\hline & $\mathbf{0 3}$ & $\mathbf{0 4}$ & $\mathbf{0 5}$ & $\mathbf{0 6}$ & $\mathbf{0 3}$ & $\mathbf{0 4}$ & $\mathbf{0 5}$ & $\mathbf{0 6}$ \\
\hline \hline Big 3 SA (Mt) & 48.4 & 52.4 & 43.8 & 42.9 & 60 & 60 & 60 & 60 \\
\hline Big 3 Col (Mt) & 25 & 25 & 26 & 28 & 25 & 25 & 26 & 28 \\
\hline Fringe (Mt) & 44.1 & 60.5 & 70.8 & 87.7 & 42.9 & 56.1 & 60.7 & 76.3 \\
\hline \hline Price (USD/t) & 69.1 & 80.4 & 77.2 & 78.7 & 57.9 & 76.7 & 70.3 & 72.2 \\
\hline
\end{tabular}

Table 3: Modeling results for the traded quantities in Mt and the prices in USD/t in from 2003 to 2006 for the Cournot oligopoly and the perfect competition cases.

In the years 2003 and 2006 the actual prices and quantities seem to be more in line with perfect competition, whereas to quantities supplied by South Africa in the Cournot simulations are significantly lower. Therefore, it seems that market power was exerted in a limited time period as a sort of "defense mechanism"2 against the new entrant Russia between mid-2004 to mid-2005. But when the optimal withholding became too great or would have attracted more entrants the market became competitive again in the second half of 2005. This is in line with the results of Haftendorn and Holz (2010) where perfect competition better represents the global trade flows in 2005 and 2006.

In this analysis we considered only the benefit the "big three" may have had by using market power through quantity. However as we have observed in Section 4 this quantity effect may have been accompanied by an unusual increase of Colombian

\footnotetext{
${ }^{2}$ An alternative strategy of the incumbent cartel could have been to flood the market to prevent the entry of competitors. This was however not possible due to production and export capacity limitations.
} 
(and to some extend South African) F.O.B. prices. Higher Colombian prices would make the quantity effect stronger or require less of a quantity effect for the same amount of additional profit. However there is no theoretical model to our knowledge where such a divergence can be reproduced without breaking some assumption of the perfect market, especially perfect information and rationality of players.

\section{Conclusions}

Integrating market power in large scale numerical partial equilibrium models is a difficult undertaking. We have shown that a widely used approach using the theory of conjectural variations (CV) that we called mixed aggregated conjectural variation (MACV) modeling fails to properly represent rational players exerting market power and may lead to counter-intuitive results where the players exerting market power are worse-off than if they had behaved competitively. This is due to the equilibrium conditions of the MACV model that constrain the player to a given relative mark-up. In the case that all the players have market power these condition represent the profit maximizing Cournot-Nash equilibrium. However when heterogeneous strategic behavior is assumed, the MACV model fails to represent profit maximizing strategies because rational players would want to choose another relative mark-up value to maximize their profits.

Given these shortcomings we have presented alternative modeling approaches based on the Stackelberg model that ensure profit maximizing strategies of the players exercising market power because they are fully aware of the reaction of the fringe players. This approach was applied to the Atlantic steam coal market in 2004 and 2005 where some unusual price and quantity effects occurred that may have been due to the strategic behavior of the "big three" dominant companies. Different market structure scenarios were implemented to model the dominant oligopoly: a non-cooperative Cournot-Nash model and two cooperative models (cartel and Nash bargaining competition). We find evidence that the oligopoly composed of the three mining companies BHP Billiton, Anglo American and Xstrata exerted market power in a non-cooperative way between in 2004 and 2005 by withholding supplies from South Africa in order to keep more expensive fringe players as price setters. The motivation for this strategic behavior is induced by the entry and the production capacity expansions of a new fringe producer, Russia.

We find this exercise of market power to be an occurrence limited in time as in the years 2003 and 2006 a competitive model is a better representation of the actual market outcome. Also this punctual strategic behavior does not seem to be an issue that would require the action of competition authorities since entry in the market 
is relatively easy. Static models can deliver some insights in market power issues but in our case more complex models where capacities are not fixed could also be helpful to analyze the investment and entry dynamics. 


\section{References}

Baruya, Paul. 2007. Supply costs for internationally traded coal. London: IEA Clean Coal Centre.

Bowley, A. L. 1924. The Mathematical Groundwork of Economics : an Introductory Treatise. Clarendon Press, Oxford.

Bresnahan, Timothy F. 1981. "Duopoly Models with Consistent Conjectures." The American Economic Review 71(5):934-945.

Bushnell, James. 2003. "A Mixed Complementarity Model of Hydrothermal Electricity Competition in the Western United States." Operations Research 51(1):80-93.

Chen, Yishu H., Benjamin F. Hobbs, Todd S. Munson and Sven Leyffer. 2006. "Leader-Follower Equilibria for Electric Power and NOx Allowances Markets." Computational Management Science 3(4):307-330.

Daughety, Andrew F. 1985. "Reconsidering Cournot: The Cournot Equilibrium is Consistent." The RAND Journal of Economics 16(3):368-379.

DeMiguel, Victor and Huifu Xu. 2009. "A Stochastic Multiple-Leader Stackelberg Model: Analysis, Computation, and Application." Operations Research .

Dirkse, Steven P. and Michael C. Ferris. 1999. "Modeling and Solution Environments for MPEC: GAMS and MATLAB." In: Fukushima, Masao and Liqun Qi (eds.), Reformulation: nonsmooth, piecewise smooth, semismooth, and smoothing methods, Kluwer Academic Publishers, Applied Optimization, 127-147.

Dockner, Engelbert J. 1992. "A Dynamic Theory of Conjectural Variations." The Journal of Industrial Economics 40(4):377-395.

Egging, Ruud, Steven A. Gabriel, Franziska Holz and Jifang Zhuang. 2008. "A Complementarity Model for the European Natural Gas Market." Energy Policy $36(7): 2385-2414$.

Egging, Ruud, Franziska Holz and Steven A. Gabriel. 2010. "The World Gas Model: A Multi-Period Mixed Complementarity Model for the Global Natural Gas Market." Energy 35(10):4016-4029.

Ehrenmann, Andreas. 2004. Equilibrium Problems with Equilibrium Constraints. Ph.D. thesis, University of Cambridge. 
Ekawan, Rudianto and Michel Duchêne. 2006. "The Evolution of Hard Coal trade in the Atlantic market." Energy Policy 34(13):1487-1498.

Ferris, Michael C., Steven P. Dirkse and Alexander Meeraus. 2002. "Mathematical Programs with Equilibrium Constraints: Automatic Reformulation and Solution via Constrained Optimization."

Ferris, Michael C. and Todd S. Munson. 2000. "Complementarity Problems in GAMS and the PATH Solver." Journal of Economic Dynamics and Control 24(2):165-88.

Figuières, Charles (ed.). 2004. Theory of Conjectural Variations. Number 2 in Series on mathematical economics and game theory, Singapore: World Scientifc.

Friedman, James W. 1983. Oligopoly Theory. Cambridge: Cambridge University Press.

Frisch, Ragnar. 1933. "Monopole - Polypole - La Notion de Force dans l'Economie." Tilløgshefte til Nationaløkonomisk Tidsskrift 71:241-259.

Gabriel, Steven. A. and Yves Smeers. 2006. "Complementarity Problems in Restructured Natural Gas Markets." In: Seeger, A. (ed.), Lecture Notes in Economics and Mathematical Systems, Berlin/Heidelberg: Springer, Recent Advances in Optimization, 343-373.

Graham, Paul, Sally Thorpe and Lindsay Hogan. 1999. "Non-competitive market behaviour in the international coking coal market." Energy Economics 21(3):195212.

Haftendorn, Clemens and Franziska Holz. 2010. "Modeling and Analysis of the International Steam Coal Trade." The Energy Journal 31(4):201-225.

Harrington, J. E., Benjamin F. Hobbs, Jong-Shi Pang, A. Liu and G. Roch. 2005. "Collusive Game Solutions via Optimization." Math. Program. 407-435.

IEA. 2011. Coal Information 2011. Paris: OECD.

Kawaguchi, Tsunemasa, Nobuhiro Suzuki and Harry M. Kaiser. 1997. "A Spatial Equilibrium Model for Imperfectly Competitive Milk Markets." American Journal of Agricultural Economics 79(3):851-859.

Kolstad, Charles D. and David S. Abbey. 1984. "The Effect of Market Conduct on International Steam Coal Trade." European Economic Review 24(1):39-59. 
Kolstad, Charles D., David S. Abbey and Robert L. Bivins. 1983. "Modeling International Steam Coal Trade." Los Alamos National Laboratory.

Kolstad, Charles D. and Anthony E. Burris. 1986. "Imperfectly Competitive Equilibria in International Commodity Markets." American Journal of Agricultural Economics 68(1):27-36.

Kolstad, Charles D. and Frank A. Wolak. 1983. "Competition in Interregional Taxation: The Case of Western Coal." Journal of Political Economy 91(3):443-460.

Kolstad, Charles D. and Frank A. Wolak. 1985. "Strategy and Market Structure in Western Coal Taxation." The Review of Economics and Statistics 67(2):239-249.

Kolstad, Charles D. and Frank A. Wolak. 1986. "Conjectural Variation and the Indeterminacy of Duopolistic Equilibria." The Canadian Journal of Economics Revue canadienne d'Economique 19(4):656-677.

Laitner, John. 1980. "Rational" Duopoly Equilibria." The Quarterly Journal of Economics 95(4):641-662.

Lindh, Thomas. 1992. "The Inconsistency of Consistent Conjectures : Coming back to Cournot." Journal of Economic Behavior \& Organization 18(1):69-90.

Makowski, Louis. 1987. "Are 'Rational Conjectures' Rational?" The Journal of Industrial Economics 36(1):35-47, URL http://www.jstor.org/stable/2098595.

Nelson, Carl H. and Bruce A. McCarl. 1984. "Including Imperfect Competition in Spatial Equilibrium Models." Canadian Journal of Agricultural Economics/Revue canadienne d'agroeconomie 32(1):55-70.

Paulus, Moritz and Johannes Trüby. 2011. "Market Structure Scenarios in International Steam Coal Trade." EWI Working Paper 2011/02.

Paulus, Moritz, Johannes Trüby and Christian Growitsch. 2011. "Nations as Strategic Players in Global Commodity Markets: Evidence from World Coal Trade." EWI Working Paper 2011/04.

Perry, Martin K. 1982. "Oligopoly and Consistent Conjectural Variations." The Bell Journal of Economics 13(1):197-205.

Ralph, Daniel and Yves Smeers. 2006. "EPECs as models for electricity markets." IEEE, 2006 IEEE PES Power Systems Conference and Exposition, 74-80. 
Ritschel, Wolfgang and Hans-Wilhelm Schiffer. 2007. "World Market for Hard Coal, 2007 Edition." RWE Power, Essen/Cologne.

Sherali, Hanif D. 1984. "A Multiple Leader Stackelberg Model and Analysis." Operations Research 32(2):390-404.

Smeers, Yves. 2008. "Gas models and three difficult objectives." CORE Discussion Papers 2008009, Université catholique de Louvain, Center for Operations Research and Econometrics (CORE).

Stackelberg, Heinrich. 1934. Marktform und Gleichgewicht. Vienna: Julius Springer.

Ulph, A. M. and G. M. Folie. 1980. "Economic Implications of Stackelberg and NashCournot Equilibria." Journal of Economics 40:343-354, 10.1007/BF01283209.

Vives, Xavier. 2000. Oligopoly Pricing - Old Ideas and New Tools. Cambridge, Mass.: MIT Press.

$\mathrm{Xu}$, Huifu. 2005. "An MPCC approach for stochastic Stackelberg-Nash-Cournot equilibrium." Optimization 54(1):27-57.

Zwart, Gijsbert and Machiel Mulder. 2006. "NATGAS: A Model of the European Natural Gas Market." CPB Memorandum 144. 


\section{Appendix 1}

\section{Proof of proposition 1}

Given the first order-conditions: $b-2 q_{i}-q_{j}-C \prime\left(q_{i}\right)-r_{i} q_{i}=0$ and $b-2 q_{j}-q_{i}-C \prime\left(q_{j}\right)-r_{j} q_{j}=0$, and symmetry $\left(C \prime\left(q_{i}\right)=C \prime\left(q_{j}\right)=c\right)$ we obtain following expressions:

$q_{j}=\frac{b-q_{i}-c}{2+r_{j}}$ and $r_{i}=\frac{-b+2 q_{i}+q_{j}+c}{-q_{i}}$

Replacing the expression of $q_{j}$ in $r_{i}$ yields following expression for $r_{i}$ :

$r_{i}=-2+\frac{1}{2+r_{j}}-\frac{-b+c+\frac{b}{2+r_{j}}-\frac{c}{2+r_{j}}}{q_{i}}$

Now to obtain the obtain the profit maximizing value of $q_{i}$ we modify the optimization problem of player $i$ by integrating the above expression of $q_{i}$, so that the firm can choose its profit-maximizing quantity given the other firms $\mathrm{CV} r_{j}$ :

$\max _{q_{i}} \Pi_{i}=\left[b-\left(q_{i}+\frac{b-q_{i}-c}{2+r_{j}}\right)\right] q_{i}-C\left(q_{i}\right)$

$\frac{\partial \Pi_{i}}{\partial q_{i}}=b-q_{i}-\frac{b-q_{i}-c}{2+r_{j}}+\left(-1+\frac{1}{2+r_{j}}\right) q_{i}-c=0$

$q_{i}=\frac{-b+c-b r_{j}+c r_{j}}{-2-2_{j}}$

Integrating this expression of $q_{i}$ in the above expression of $r_{i}$, yields, after simplification:

$r_{i}=-\frac{1}{2+r_{j}}$

\section{Proof of proposition 2}

Assuming that the capacity constraint $K_{j} \geqslant q_{j}$ of player $j$ is binding then $K_{j}=q_{j}$. Then expression $r_{i}$ from the proof of proposition 1 can be rewritten as:

$r_{i}=-2-\frac{-b+c+K_{j}}{q_{i}}$

Accordingly, the new optimization problem of player $i$ is:

$$
\begin{aligned}
& \max _{q_{i}} \Pi_{i}=\left[b-\left(q_{i}+K_{j}\right)\right] q_{i}-C\left(q_{i}\right) \\
& \frac{\partial \Pi_{i}}{\partial q_{i}}=b-2 q_{i}-K_{j}-c=0 \\
& q_{i}=\frac{b-K_{j}-c}{2}
\end{aligned}
$$


Integrating this expression of $q_{i}$ in the above expression of $r_{i}$, yields, after simplification:

$r_{i}=0$

If the capacity is not binding when $r_{i}=0$, given any $r_{j}$, then it will never be since $\partial q_{j}^{*} / \partial r_{i}>0$. A reduction of $r_{i}$ leads to a lower $q_{j}^{*}$.

\section{Proof of proposition 3}

Assuming now that the firm are asymmetric with heterogeneous cost functions of the form $C\left(q_{i}\right)=\left(\operatorname{Cint}_{i}+{ }^{1 / 2} C \operatorname{slp}_{i} q_{i}\right) q_{i}$ with Cint $_{i} \geqslant 0$ the marginal cost's intercept and $C s l p_{i}>0$ the marginal cost's slope, we obtain:

$q_{j}=\frac{b-q_{i}-\text { Cint }_{j}}{2+r_{j}+C s l p_{j}}$ and $r_{i}=\frac{b-2 q_{i}-q_{j}-\text { Cint }_{i}-C s l p_{i} q_{i}}{-q_{i}}$

Replacing the expression of $q_{j}$ in $r_{i}$ yields following expression for $r_{i}$ :

$r_{i}=-2-C s l p_{i}+\frac{1}{2+C s l p_{j}+r_{j}}-\frac{b-C i n t_{i}-\frac{b}{2+C s l p_{j}+r_{j}}-\frac{C i n t_{j}}{2+C s l p_{j}+r_{j}}}{q_{i}}$

Now to obtain the obtain the profit maximizing value of $q_{i}$ modify the optimization problem of player $i$ by integrating the above expression of $q_{i}$, so that the firm can choose its profit-maximizing quantity given the other firms $\mathrm{CV} r_{j}$ :

$\max _{q_{i}} \Pi_{i}=\left[b-\left(q_{i}+\frac{b-q_{i}-\text { Cint }_{j}}{2+r_{j}+C s l p_{j}}\right)\right] q_{i}-\left(\operatorname{Cint}_{i}+{ }_{1}^{1 / 2} \operatorname{Csl} p_{i} q_{i}\right) q_{i}$

$\frac{\partial \Pi_{i}}{\partial q_{i}}=b-q_{i}-\frac{b-q_{i}-\operatorname{Cint}_{j}}{2+r_{j}+C s l p_{j}}+\left(-1+\frac{1}{2+r_{j}+C s l p_{j}}\right) q_{i}-$ Cint $_{i}-\operatorname{Cslp}_{i} q_{i}=0$

$q_{i}=\left(b-C i n t_{i}-\frac{b}{2+r_{j}+C s l_{j}}+\frac{\operatorname{Cint}_{j}}{2+r_{j}+C s l_{j}}\right) /\left(2+C s l p_{i}-\frac{2}{+r_{j}+C s l p_{j}}\right)$

Integrating this expression of $q_{i}$ in the above expression of $r_{i}$, yields, after simplification:

$r_{i}=-\frac{1}{2+C s l p_{j}+r_{j}}$

If for the calculated value of $r_{i}, q_{j}=0$ because $p<C i n t_{j}$, then since $\partial q_{i}^{*} / \partial r_{i}<0$ and $\partial q_{i}^{*} / \partial r_{j}>0$ and because $C s l p_{i}>0$, player $i$ can increase it's profit by reducing it's quantity and increasing the market price until $p+\epsilon=$ Cint $_{j}$ with $\epsilon$ an infinitesimally small number, which represents the limit-pricing strategy. 


\section{Proof of proposition 4}

Assuming two firms $i=1,2$ that are symmetric with zero production costs and $a$ and $b$ respectively the demand curve slope and intercept. The profit function $\Pi_{1}$ is:

$\Pi_{1}=\left(b-a\left(q_{1}+q_{2}\right)\right) \cdot q_{1}$

The first order condition is:

$\frac{\partial \Pi_{1}}{\partial q_{1}}=b-a\left(q_{1}+q_{2}\right)-a \cdot q_{1}=0$

Using the symmetry of the player $q_{1}=q_{2}$, then $q_{i}^{N}=\frac{b}{3 a}$ and $\Pi_{i}^{N}=\frac{b^{2}}{9 a}$. This is the non-cooperative Cournot-Nash solution we will use for the following Nash Bargaining game, still assuming symmetry:

$\Pi^{N B}=\left(\left(b-2 \cdot a \cdot q_{i}\right) \cdot q_{i}-\frac{b^{2}}{9 a}\right) \cdot\left(\left(b-2 \cdot a \cdot q_{i}\right) \cdot q_{i}-\frac{b^{2}}{9 a}\right)$

$\frac{\partial \Pi_{N B}}{\partial q_{i}}=\left(\left(b-2 \cdot a \cdot q_{i}\right) \cdot q_{i}-\frac{b^{2}}{9 a}\right) \cdot\left(b-2 \cdot a \cdot q_{i}-2 \cdot a \cdot q_{i}\right) \cdot 2=0$

The above equation has multiple solution. However since we want the players to be better off than in the Cournot case the first expression of the product has to be positive, hence:

$b-2 \cdot a \cdot q_{i}-2 \cdot a \cdot q_{i}=0$, therefore $q_{i}^{N B}=\frac{b}{4 a}$.

Now the we calculate the results for the Cartel model with $q_{1}+q_{2}=Q$ :

$\Pi^{C}=(b-a \cdot Q) \cdot Q$

$\frac{\partial \Pi^{C}}{\partial Q}=b-a \cdot Q-a \cdot Q=0$

Thus $Q=\frac{b}{2 a}$ and $q_{i}^{C}=\frac{Q}{2}=\frac{b}{4 a}$.

We therefore proved that $q_{i}^{C}=q_{i}^{N B}=\frac{b}{4 a}$. 


\section{Appendix 2}

\begin{tabular}{|l|c|c|c|c|c|c|c|c|}
\hline & $\mathbf{2 0 0 2}$ & $\mathbf{2 0 0 3}$ & $\mathbf{2 0 0 4}$ & $\mathbf{2 0 0 5}$ & $\mathbf{2 0 0 6}$ & $\mathbf{2 0 0 7}$ & $\mathbf{2 0 0 8}$ & $\mathbf{2 0 0 9}$ \\
\hline To Europe & & & & & & & & \\
\hline South Africa & 54.5 & 58.9 & 55.9 & 53.0 & 55.2 & 48.6 & 38.4 & 30.6 \\
\hline Colombia & 21.4 & 24.5 & 25.6 & 26.5 & 28.5 & 31.8 & 29.8 & 34.0 \\
\hline Russia & 22.7 & 28.5 & 41.3 & 48.7 & 58.0 & 60.0 & 60.4 & 61.1 \\
\hline US & 4.5 & 2.5 & 3.7 & 2.4 & 3.4 & 5.5 & 12.9 & 11.1 \\
\hline Indonesia & 11.0 & 12.4 & 13.6 & 14.2 & 20.6 & 17.1 & 15.5 & 12.8 \\
\hline Australia & 9.8 & 12.2 & 10.4 & 7.6 & 6.5 & 7.7 & 6.4 & 5.0 \\
\hline Sum & 123.9 & 139.0 & 150.5 & 152.4 & 172.1 & 170.7 & 163.5 & 154.6 \\
\hline S. Afr.+Col. & 75.9 & 83.4 & 81.5 & 79.5 & 83.7 & 80.3 & 68.2 & 64.5 \\
\hline $\begin{array}{l}\text { Share } \\
\text { S. Afr.+Col. }\end{array}$ & 0.61 & 0.60 & 0.54 & 0.52 & 0.49 & 0.47 & 0.42 & 0.42 \\
\hline & & & & & & & & \\
\hline To India & & & & & & & & \\
\hline South Africa & 3.8 & 2.9 & 0.7 & 2.4 & 3.6 & 7.7 & 7.8 & 20.6 \\
\hline
\end{tabular}

Table 4: Steam coal trade flows to Europe in million tons and import market share of South Africa and Colombia (Source: Coal Information IEA, 2011)

\begin{tabular}{|l|c|c|c|c|c|c|c|}
\hline & $\mathbf{2 0 0 2}$ & $\mathbf{2 0 0 3}$ & $\mathbf{2 0 0 4}$ & $\mathbf{2 0 0 5}$ & $\mathbf{2 0 0 6}$ & $\mathbf{2 0 0 7}$ & $\mathbf{2 0 0 8}$ \\
\hline South Africa & & & & & & & \\
\hline Anglo American & 15.7 & 18.6 & 17.4 & 20.3 & 22.8 & 24.0 & 22.3 \\
\hline BHP Billition & 23.6 & 22.8 & 20.5 & 21.9 & 20.3 & 18.8 & 12.4 \\
\hline Xstrata & 12.6 & 13.8 & 12.9 & 13.5 & 13.2 & 13.7 & 12.3 \\
\hline Total S.A. Exports & 68.5 & 70.9 & 67.0 & 70.9 & 68.1 & 65.1 & 59.4 \\
\hline Total Big 3 & 52 & 55 & 51 & 56 & 56 & 56 & 47 \\
\hline Share Big 3 & 0.76 & 0.78 & 0.76 & 0.78 & 0.83 & 0.87 & 0.79 \\
\hline & & & & & & & \\
\hline Colombia & & & & & & & \\
\hline Anglo American & 6.9 & 8.7 & 9.6 & 10.1 & 11.0 & 11.3 & 11.5 \\
\hline BHP Billition & 5.4 & 8.2 & 8.2 & 8.7 & 9.5 & 9.9 & 10.5 \\
\hline Xstrata & & & & & 9.2 & 9.9 & 10.5 \\
\hline Glencore & 6.0 & 8.0 & 9.7 & 8.5 & & & \\
\hline Prodeco (Glencore) & 5.0 & 5.0 & 5.0 & 5.0 & 5.0 & 13.5 & 13.5 \\
\hline Total Col. Exports & 36.5 & 45.6 & 50.9 & 53.6 & 62.0 & 64.6 & 67.8 \\
\hline Total Big 3 & 30.3 & 38.6 & 42.1 & 42.3 & 45.7 & 55.8 & 57.5 \\
\hline Share Big 3 & 0.83 & 0.85 & 0.83 & 0.79 & 0.74 & 0.86 & 0.85 \\
\hline
\end{tabular}

Table 5: Export volumes in million tons and export market share of the "Big Three" (Source: company annual reports 2002-2008) 